ARTICLE

\title{
Xrn1 is a deNADding enzyme modulating mitochondrial NAD-capped RNA
}

Sunny Sharma ${ }^{1}$, Jun Yang ${ }^{1}$, Ewa Grudzien-Nogalska ${ }^{1}$, Jessica Shivas ${ }^{1}, K^{2}$ Kelvin Y. Kwan (D) ${ }^{1}$ \& Megerditch Kiledjian (1) ${ }^{1 凶}$

The existence of non-canonical nicotinamide adenine diphosphate (NAD) 5'-end capped RNAs is now well established. Nevertheless, the biological function of this nucleotide metabolite cap remains elusive. Here, we show that the yeast Saccharomyces cerevisiae cytoplasmic $5^{\prime}$-end exoribonuclease Xrn1 is also a NAD cap decapping (deNADding) enzyme that releases intact NAD and subsequently degrades the RNA. The significance of Xrn1 deNADding is evident in a deNADding deficient Xrn1 mutant that predominantly still retains its 5'-monophosphate exonuclease activity. This mutant reveals Xrn1 deNADding is necessary for normal growth on non-fermenting sugar and is involved in modulating mitochondrial NAD-capped RNA levels and may influence intramitochondrial NAD levels. Our findings uncover a contribution of mitochondrial NAD-capped RNAs in overall NAD regulation with the deNADding activity of $\mathrm{Xrn1}$ fulfilling a central role.

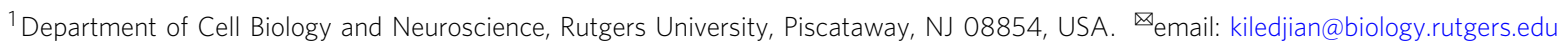


$\mathrm{N}$ ucleotide metabolites serve as cofactors for multiple enzymatic activities essential for cellular survival and propagation $^{1}$. Recent demonstrations of the redox cofactor NAD covalently linked to the $5^{\prime}$-end of RNAs as an RNA cap in bacteria, yeast, plants, and mammals have uncovered a modulatory network where a metabolite can directly impact gene expression $^{2-5}$. Biochemical studies in prokaryotes have shown that bacterial polymerases can add an NAD cap in place of ATP at the $5^{\prime}$-end during transcription initiation ${ }^{6}$. On the other hand, detection of an NAD cap on post-transcriptionally processed intronic small nucleolar RNAs (snoRNAs) in mammalian cells has advocated the existence of a post-transcriptional NAD-capping mechanism as well ${ }^{3}$. These studies have also led to the identification of a battery of NAD-cap decapping (deNADding) enzymes-NudC in bacteria $2,7,8$ and its human homolog Nudt $12^{9,10}$, Nudt $16^{10}$ and the DXO/Rail family of non-canonical decapping enzymes ${ }^{3,11}$. DXO/Rail are class 1 deNADding enzymes that target the phosphodiester linkage and releases an intact NAD while NudC, Nudt12, and Nud16 are class 2 deNADding enzymes that hydrolyze the pyrophosphate bond within the NAD of the NAD cap and release nicotinamide mononucleotide $(\mathrm{NMN})^{9,12}$.

Functional analyses of the NAD-capped RNAs have revealed disparate roles in bacterial and mammalian cells. In bacteria, the NAD cap is considered to protect the RNA from $5^{\prime}$-end degradation ${ }^{2}$, whereas in mammals ${ }^{3}$ and plants ${ }^{13}$ NAD caps have been shown to promote RNA decay. In bacteria, NAD caps are found on certain regulatory $\mathrm{RNAs}^{2}$, while in budding yeast Saccharomyces cerevisiae, they are on a subset of mitochondrial RNAs and transcripts encoding the translational machinery ${ }^{4}$. NAD-capped RNAs are prevalent in the transcriptome of plants ${ }^{5}$ and human cells ${ }^{3}$, and are mainly comprised of mRNAs and small nucleolar RNAs (snoRNAs). The NAD cap does not appear to support translation in mammalian cells ${ }^{3}$, while their presence on plant polysomes indicates a translational capacity ${ }^{5}$. Despite the occurrence of NAD caps in diverse organisms, the biological role of this non-canonical metabolite cap in cellular physiology has remained elusive.

\section{Results}

Identification of Xrn1 and Rat1 as NAD cap associated proteins. To begin unraveling the functional role of NAD caps, we set out to identify proteins that specifically bind to the NAD cap. Protein purification was carried out by $5^{\prime}$ NAD cap RNA Affinity Purification (NcRAP) with the RNA containing a $3^{\prime}$-biotin to immobilize the affinity matrix and identify proteins associated with the NAD cap from $S$. cerevisiae lysate as illustrated in Fig. 1a. Canonical $\mathrm{m}^{7} \mathrm{G}$-capped RNA was used as a control for the cap affinity purification and associated proteins were identified by mass spectrometry. As expected, the nuclear (Sto1 and CBC2) and cytoplasmic (eIF4E) canonical cap-binding proteins were prominent bands selectively detected on the $\mathrm{m}^{7} \mathrm{G}$ cap RNA affinity column as well as the associated eIF4F adapter complex proteins eIF4G1 and eIF4G2 ${ }^{14}$ (Fig. $1 \mathrm{~b}$ and Supplementary Fig. 1a), demonstrating the feasibility of the NcRAP approach.

Mass spectrometry identification of proteins selectively bound to the NAD-capped RNA (Supplementary Data 1) revealed surprising candidates. The most prominent protein interacting with the NAD cap was the cytoplasmic $5^{\prime}-3^{\prime}$ exoribonucleases $\operatorname{Xrn}^{15}$ (Fig. 1b). Additional prominent bands unique to the NAD cap lane included the nuclear $5^{\prime}-3^{\prime}$ exoribonucleases Rat1 (Xrn2 in mammals) ${ }^{16,17}$ and the Rat 1 interacting partner, Rail ${ }^{18}$ (Fig. $1 \mathrm{~b}$ and Supplementary Fig. 1a). These interactions were further validated by performing NcRAP using protein lysates derived from an Xrn1 deletion $(x r n 1 \Delta)$ strain. In the absence of Xrn1, binding of both the
Rat1 and Rail proteins to the NAD cap was accentuated. Moreover, since Rat1 and Rail exist as heterodimers ${ }^{18}$ and Rail is a known deNADding protein ${ }^{3}$, extract from the rail $\Delta$ strain was used in NcRAP. As shown in Supplementary Fig. 1b, the association of Rat1 with the NAD cap was independent of its interaction with the Rail based on its retention onto the NADcapped RNA column. These findings reveal Xrn1, Rat1 and Rail are capable of selectively binding to the NAD cap under the assay conditions employed.

Xrn1 and Rat1 hydrolyze NAD-capped RNAs in vitro. Identification of Xrn1 and Rat1 by NcRAP in addition to Rail, a potent deNADding enzyme ${ }^{3}$, raised the intriguing possibility that analogous to Rail, Xrn1 and Rat1 may also possess deNADding activity. Since both Xrn1 and Ratl are highly processive $5^{\prime}$ monophosphate $\left(5^{\prime} \mathrm{P}\right)$-specific $5^{\prime}-3^{\prime}$ exoribonucleases ${ }^{15,17}$, we assessed the potential of these enzymes to hydrolyze $5^{\prime} \mathrm{NAD}$ capped RNA (Fig. 2a) in vitro. As expected, Xrn1 efficiently degraded 5'P RNA (Fig. 2b) but not a 5'-triphosphate- or an $\mathrm{m}^{7} \mathrm{G}$-capped RNA (Supplementary Fig. 2a). Importantly, uniformly ${ }^{32} \mathrm{P}$-labeled NAD-capped RNA was degraded by wild-type Kluyveromyces lactis (Fig. 2b) and S.cerevisiae (Fig. 2b) Xrn1, but not the catalytically inactive $x r n 1-E 178 Q^{19}$ mutant protein. Interestingly, the decay activity of Xrn1 on NAD-capped RNA was processive without detectable intermediates in contrast to Schizosaccharomyces pombe Rail, which removed the NAD cap without subsequent degradation of the deNADded RNA (Fig. 2b), consistent with our previous report ${ }^{3}$. Similarly, S.pombe Rat1 also hydrolyzed the NAD-capped RNA with processive exonuclease activity, whereas the catalytically dead rat $1-E 207 Q^{20}$ was inactive (Fig. 2c). Collectively, these data demonstrate that the observed degradation of the NAD-capped RNA is a function of Xrn1 and Rat1, and requires the same catalytic active site utilized for the hydrolysis of a $5^{\prime} \mathrm{P}$ RNA.

To further understand the kinetics of deNADding, a timecourse decay assay was carried out with $5^{\prime} \mathrm{P}$ - or NAD-capped RNA using two different concentrations of Xrn1 and Rat1. Consistent with the well characterized exoribonuclease activities of Xrn1 and Rat1, both effectively degraded 5'P RNA (Fig. 2d). Importantly, the activity of Xrn1 on $5^{\prime} \mathrm{P}$ RNA was 20 fold more efficient than NAD-capped RNA at comparable enzyme concentrations (Fig. 2d and Supplementary Fig. 2d). Furthermore, Xrn1 degraded the NAD-capped RNA twice as efficiently as Rat1. To assess whether Xrn1 hydrolyzed the NAD cap within the diphosphate moiety analogous to the class 2 Nudt12 protein, or removed the intact NAD, similar to the class $1 \mathrm{DXO} /$ Rail family of proteins ${ }^{12}$, thin layer chromatography (TLC) was used. Interestingly, ${ }^{32} \mathrm{P}$-labeled NAD-capped RNA subjected to Xrn1 or Rat1 hydrolysis released intact NAD (Fig. 2e). In addition, unlike Nudt12 both Xrn1 and Rat1 do not hydrolyze the diphosphate bond of free NAD (Supplementary Fig. 2e). We conclude that Xrn1 and Rat1 are class 1 deNADding enzymes that have the capacity to degrade NAD-capped RNA analogous to the DXO/Rail family of proteins by removing the intact NAD (Fig. 2f). These findings increase the repertoire of substrate RNAs regulated by Xrn1 and Rat1 beyond their well characterized $5^{\prime}$ monophosphate directed exoribonuclease activity. Moreover, the deNADding activity of Xrn1 is not restricted to yeast, as shown in Supplementary Fig. 2f, human Xrn1 also hydrolyzes NADcapped RNAs.

Loss of Xrn1 stabilizes NAD-capped RNAs in vitro and in vivo. Having demonstrated Xrn1 and Rat1 function as deNADding enzymes in vitro, we assessed the deNADding activity of Xrn1 in cells. We focused on $\operatorname{Xrn} 1$ since the $\operatorname{xrn} 1 \Delta$ strain is viable and 
a

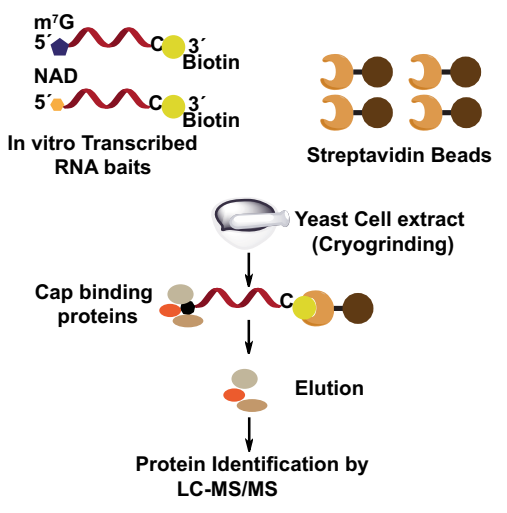

b

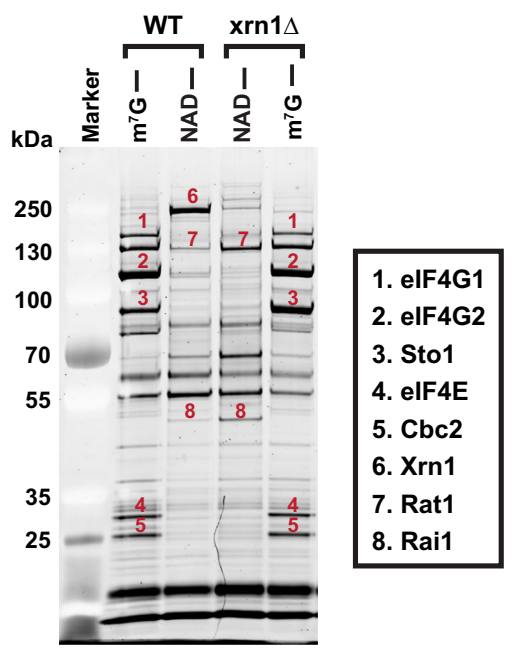

Fig. 1 Identification of NAD cap-binding proteins in budding yeast. a Schematic illustration of the NAD cap -RNA Affinity Purification (NcRAP). b Eluates from NcRAP were loaded on to a 4-12\% Bis-Tris gel and stained with SYPRO Ruby. The $\mathrm{m}^{7} \mathrm{G}$ cap affinity purification was used as a control. All protein bands labeled on the gel were excised from the gel and identified using mass spectrometry.

amenable to genetic manipulation, while the rat1 $\Delta$ stain is $\operatorname{not}^{16}$. $5^{\prime}$-end RNA decay assays were carried out with extract derived from either wild-type (WT) or xrn1 $1 \Delta$ cells using NAD-or $\mathrm{m}^{7} \mathrm{G}$-capped RNAs immobilized and protected at the $3^{\prime}$-end with biotin-streptavidin (Fig. 3a). While no significant differences were observed with the control $\mathrm{m}^{7} \mathrm{G}$-capped RNA, the NADcapped RNA was more stable in the $x r n 1 \Delta$ extract, suggesting endogenous Xrn1 possesses deNADding activity (Fig. $3 \mathrm{~b}$ ). To assess the contribution of Xrn1 deNADding on endogenous NAD-capped RNA, we used the NAD cap detection and quantitation (NAD-capQ) approach that detects NAD caps released from the $5^{\prime}$-end of RNAs en masse (Supplementary Fig. 3a) ${ }^{21}$. Consistent with a deNADding function for Xrn1 in cells, a statistically significant 1.5 -fold higher level of total NAD cap was detected in the $x r n 1 \Delta$ strain relative to the WT strain (Fig. 3c).

Xrn1 deNADding activity influences NAD-capped mitochondrial transcripts. Previous transcriptome-wide analyses of NADcapped RNA in budding yeast identified distinct NAD-capped nuclear and mitochondrial transcripts ${ }^{4,22}$ with levels as high as $50 \%$ of select mitochondrial RNAs containing an NAD cap ${ }^{22}$. To determine whether the accumulation of endogenous NADcapped RNAs was altered in the absence of Xrn1, NAD-capped RNAs were isolated by NAD capture ${ }^{23}$ and subjected to RTqPCR analyses. We focused on a subset of previously identified NAD-capped nuclear- and mitochondrial-encoded mRNAs ${ }^{4}$. Importantly, although loss of $x \mathrm{rn} 1 \mathrm{did}$ not change the steady state accumulation of the nuclear encoded NAD-capped RNAs tested, all the mitochondrially encoded NAD-capped transcripts tested were significantly elevated (Fig. 3d). Furthermore, we validated the $\mathrm{qPCR}$ results by an independent approach using boronate affinity electrophoresis for two transcripts, Cox2 and 21S rRNA ${ }^{22}$. This method allows visualization of distinct capped and uncapped RNA populations by specifically retarding the mobility of NADcapped RNAs in the gel due to transient formation of diesters between immobilized boronic acid and the ribose moiety ${ }^{22,24}$. DNAzyme-mediated RNA cleavage was used to generate $5^{\prime}$-endcontaining subfragments of defined length (Supplementary Fig. 3b). Northern blot analysis with the ${ }^{32} \mathrm{P}$ labeled transcriptspecific probes corroborated the NAD capture analyses for Cox2 and 21S rRNA with elevated NAD-capped RNA in the $x r n 1 \Delta$ strain (Supplementary Fig. 3c). This observation prompted us to test whether Xrn1 is associated with mitochondria. In addition to its well characterized cytoplasmic localization ${ }^{25}$, Xrn1 has also been reported on cell membrane compartments called eisosomes that mark the sites of endocytosis during post-diauxic shift ${ }^{26}$. Gradient centrifugation purified mitochondria derived from a strain harboring Xrn1 with a C-terminus Strep-tag II was analyzed by Western blot analysis with an anti-Strep-tag antibody. As shown in Fig. 3e Xrn1 was detected with mitochondrial preparations suggesting Xrn1 can be mitochondrially associated.

Immunofluorescent colocalization was next used to more directly determine the localization of Xrn1. A knock-in strain of the green fluorescence protein (GFP) gene inserted in frame into the endogenous XRN1 gene analogous to that reported in ${ }^{27}$ was generated within a strain background harboring red m-cherry fluorescent peptide fused to Edc3, a P-body marker ${ }^{28}$. Consistent with a previous report ${ }^{27}$, GFP tagged Xrn1 was functional and did not exhibit any growth phenotype when grown on YPG media (Supplementary Fig. 3d). Mitochondria were stained using Mitotracker $^{\circledR}$ Deep Red FM dye. Visualization of Xrn1-GFP in conjunction with Edc3-mcherry and Mitotracker ${ }^{\circledR}$ Deep Red FM by confocal microscopy revealed four populations of Xrn1 foci (Fig. 3f). In the first, Xrn1 colocalized with the Edc3 P body marker, while in a second, Xrn1 foci were devoid of Edc3 indicating Xrn1 can be in distinct foci. A third population of foci contained an association of all three signals consistent with a previous report demonstrating the association of P-body foci with mitochondria in human cells ${ }^{29}$, while the fourth contained Xrn1 and mitochondrial network, but no Edc3-containing foci. Interestingly, we did not detect association of Edc3-containing P-body foci with mitochondria in the absence of Xrn1. These findings demonstrate the dynamic nature of Xrn1 localization within distinct foci.

Using standard confocal microscopy with a resolution of $\sim 200 \mathrm{~nm}$ shown in the left top panels of the Fig. $4 \mathrm{~g}$, a diffuse cytoplasmic distribution of Xrn1 with distinct foci was observed analogous to previous reports ${ }^{30}$. However, this level of resolution could not distinguish the extent of Xrn1 and mitochondrial colocalization. To further substantiate the Xrn1 and mitochondrial association, we performed super-resolution stochastic optical reconstruction microscopy (STORM) to visualize their localization at $10-20 \mathrm{~nm}$ resolution ${ }^{31}$. As shown with both a cross-section (left bottom panel) and Z-stacks (right panel) of Xrn1 and mitochondrial localization in Fig. 3g, the two signals are superimposable, indicating Xrnl can be localized within 
a

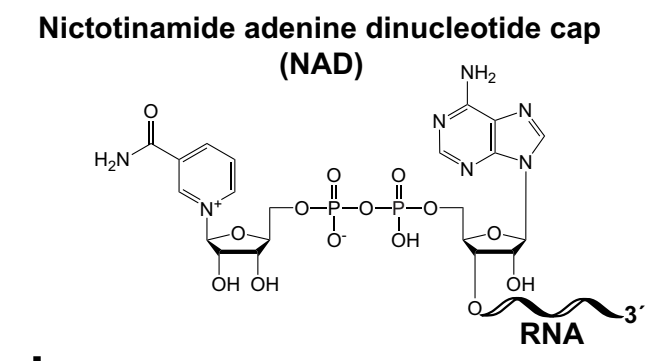

d

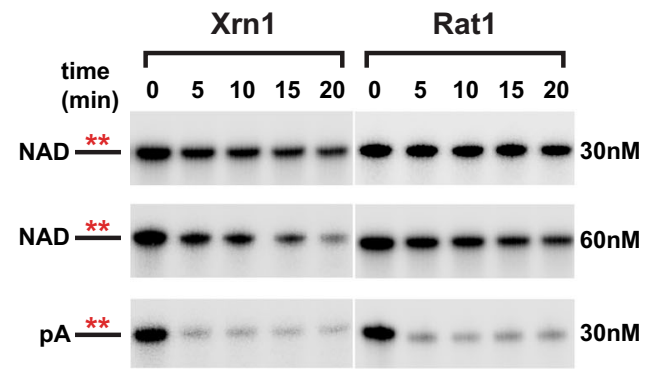

e

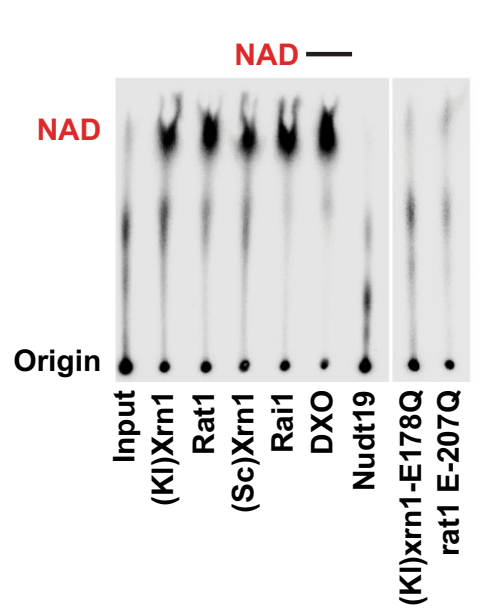

b

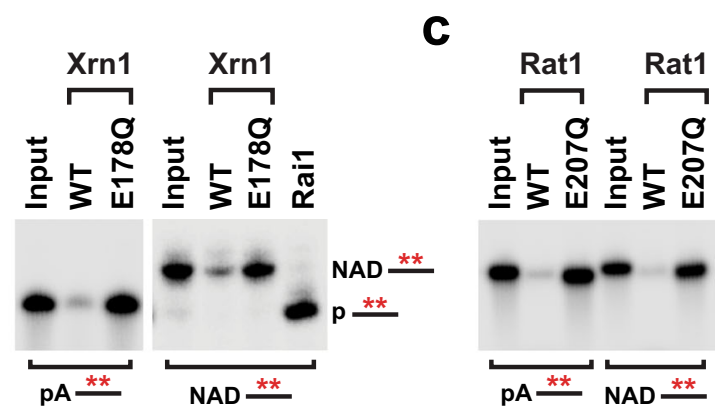

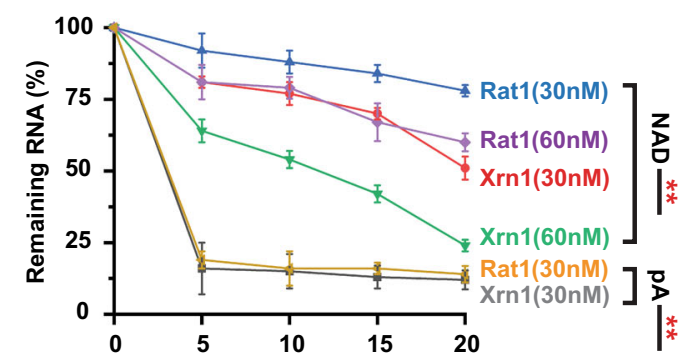

f

Fig. 2 Xrn1 and Rat1 are deNADding enzymes. a Structure of NAD-capped RNA. b Reaction products of in vitro deNADding assays with 30 nM recombinant Xrn1, WT, and catalytically inactive (E178Q) from K. lactis or $25 \mathrm{nM}$ Rai1 (S. pombe), (c) and $50 \mathrm{nM}$ recombinant Rat1, WT or catalytically inactive (E207Q) from S. pombe. Uniformly 32P-labeled monophosphate (pA----) or NAD-capped RNA (NAD---) were used as indicated and the line denotes the RNA. The red asterisk represents the ${ }^{32} \mathrm{P}$-labeling within the body of the RNA. Reaction products were resolved on $15 \% 7 \mathrm{M}$ urea PAGE gels with (b) and without (c) $0.3 \%$ 3-acrylamidophenylboronic acid. d Time-course decay analysis of uniformly ${ }^{32}$ P-labeled monophosphate or NAD-capped RNA (9pmol) with the indicated amount of Xrn1 or Rat1 ( 0.45 or $~ 0.9$ pmol, respectively) protein are shown. Quantitation of RNA remaining is plotted from $n=3$ independent experiments with \pm SD denoted by error bars. Source data are provided in Source Data File. e NAD-capped RNA containing the 32P-labeling within the $\alpha$ phosphate of the NAD (represented in red) was subjected to the indicated proteins. Decay products were resolved by polyethyleneimine (PEI)-cellulose thin layer chromatography (TLC) developed in $0.45 \mathrm{M}\left(\mathrm{NH}_{4}\right)_{2} \mathrm{SO}_{4}$. Rai1 and DXO served as positive controls, whereas Nudt19 was a negative control. f Schematic of NAD-capped RNA hydrolysis by Rai1, Xrn1, Rat1 and DXO.

mitochondria in yeast cells. Collectively, both the in vitro reconstitution and the in vivo analysis demonstrated a functional role for Xrn1 in regulating the fate of NAD-capped RNA in yeast mitochondria.

A conserved histidine residue in the catalytic pocket of Xrn1 is indispensable for NAD-capped RNA hydrolysis. Structural and functional analyses of Xrn1 from K. lactis and Drosophila melanogaster have elucidated the molecular basis of the $5^{\prime} \mathrm{P}$-specificity and the mechanism of processive RNA degradation ${ }^{19,32}$. The $5^{\prime} \mathrm{P}$ is embedded in a highly basic pocket lined with the side chains of the conserved amino acids K93, E97, R100, and R101 with His41 providing directionality to the decay process ${ }^{32}$ (Supplementary Fig. 4a). To determine whether the $5^{\prime} \mathrm{P}$ hydrolysis activity of Xrn1 can be uncoupled from the deNADding activity, a mutational screen was initiated. Structure guided point mutations were generated in the $5^{\prime} \mathrm{P}$ binding pocket and the catalytic residues assessed for their deNADding activity. Importantly, one residue, His41, was indispensable for deNADding while it still supported $5^{\prime} \mathrm{P}$ RNA decay activity (Fig. 4a, Supplementary Fig. 4b). To gauge the impact of H41A on deNADding in cells, a $x r n 1-H 41 A$ knock-in mutant strain was generated. Consistent with the in vitro analysis, the H41A mutant retained $5^{\prime} \mathrm{P}$ mediated exonuclease activity in cells as shown 
a

In vitro 5'end RNA decay

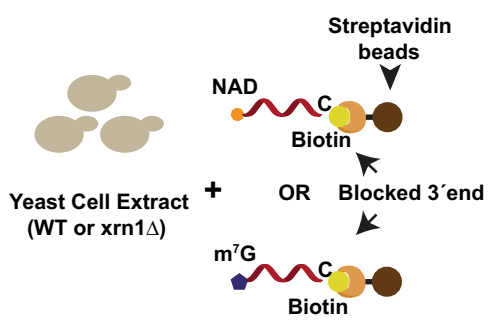

b

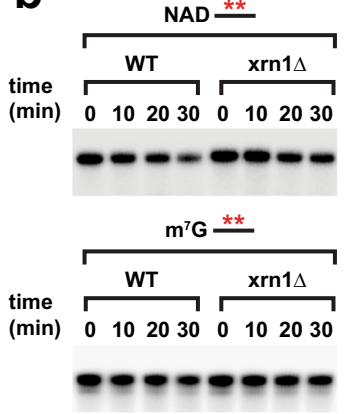

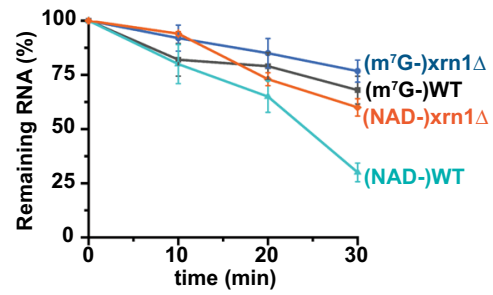

e

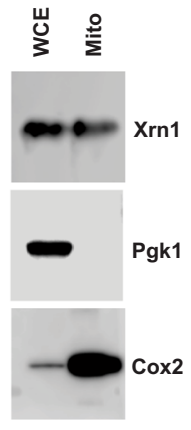

C

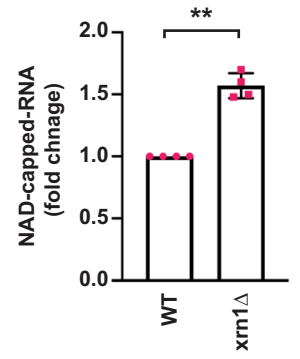

d

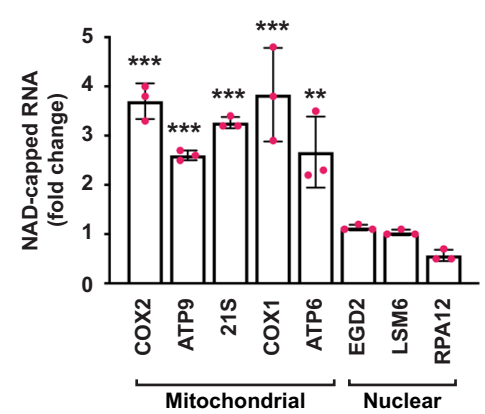

\section{g}
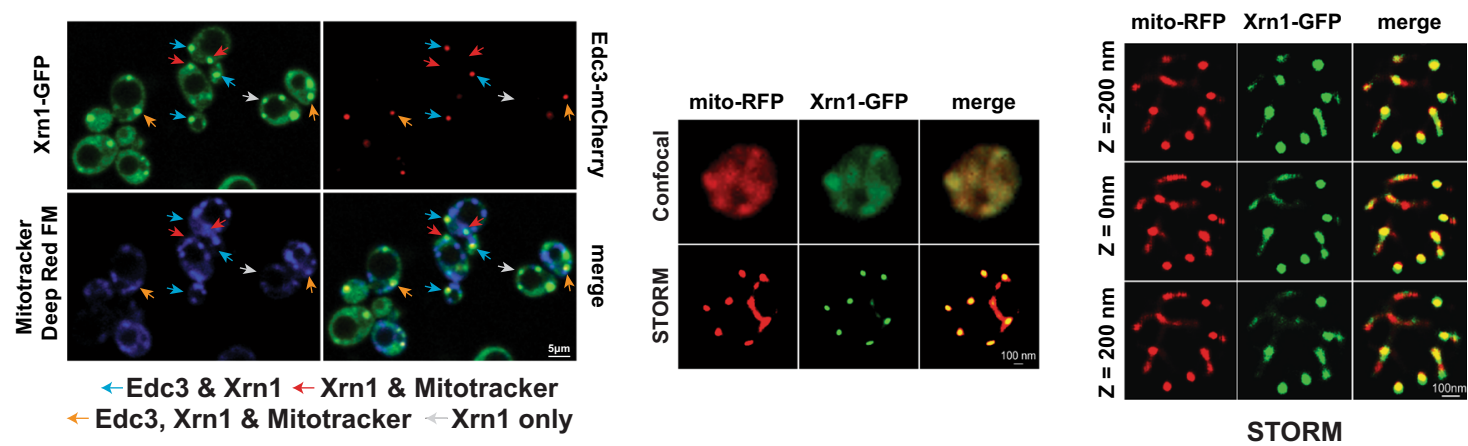

Fig. 3 Xrn1 deNADs NAD-capped RNAs in cells. a Schematic illustration of in vitro 5'-end RNA decay. $\mathbf{b}$ Time-course decay analysis of uniformly 32P-labeled $\mathrm{m}^{7} \mathrm{G}$ - or NAD-capped RNA in the presence of cell extract prepared from WT or xrn14 strains. The remaining RNA was quantified and plotted from $n=3$ independent experiments ( \pm SD denoted by error bars). Labeling as in the legend to Fig. 2. c Total NAD-capped RNA levels from WT and xrn1 $\Delta$ were detected by NAD-capQ. Data represents average from $n=4$ independent experiments. Error bars represent \pm SEM; two sided unpaired $t$ test; $\left.{ }^{\star *} p=0.0036\right)$. d $q R T$-PCR quantification of NAD-capped mRNA. NAD-capped RNA was enriched by NAD-capture, eluted from the beads, reverse transcribed and detected with gene-specific primers. Data are presented relative to the WT cells set to 1 and derived from $n=3$ independent NAD-capture experiments; mean \pm SEM; two-sided unpaired $t$ test; ${ }^{\star \star} p<0.001,{ }^{\star \star \star} p<0.0001$. e Purified mitochondria derived from a strain harboring Xrn1 with a C-terminus Strep-tag II was analyzed by Western blot analysis with an anti-Strep-tag antibody. Western blotting analysis of whole cell extract (WCE) and extract prepared from purified mitochondria (mito) using Pgk1 (cytoplasmic protein) and Cox2 (mitochondrial protein) to determine the purity of mitochondria. Source data for panels b, $c$ and $d$ are provided in Source Data File. $\mathbf{f}$ Xrn1 knock-in strain containing the gene encoding green fluorescence protein (GFP) in frame with endogenous Xrn1 was generated into the strain carrying Edc3 fused to mCherry. Colocalization of Xrn1 with mitochondria (Mitotracker ${ }^{\circledR}$ Deep Red FM) and Edc3 (mCherry) by standard confocal (40X) microscopy is shown. $\mathbf{g}$ Reconstructed STORM images. Left panel shows images from a single optical section of RFP-labeled mitochondria and GFP-labeled Xrn1 in a single yeast cell obtained by spinning disk confocal (top) and STORM imaging (bottom). Merged image shows overlap of RFP and GFP signal. Right panel shows reconstructed STORM images obtained from sequentially acquired optical sections spaced $200 \mathrm{~nm}$ apart in the $\mathrm{z}$ axis. Merged images show colocalization of signals within the $\sim 10 \mathrm{~nm} X Y$ resolution. Scale bar is $100 \mathrm{~nm}$.

by its capacity to process its natural nuclear encoded substrate, Rpl22 precursor $\mathrm{RNA}^{33}$ (Fig. 4b). In contrast, the Rpl22 precursor RNA was detected at levels comparable to $x r n 1 \Delta$ when the catalytically inactive $x r n 1$-E178Q knock-in mutant was used. Similar results were also obtained with a second Xrn1 target RNA (Rpl28 precursor mRNA $)^{27,34}$, which was also efficiently degraded by the H41A mutant of Xrn1 (Fig. 4c). We next tested the consequence of a
deNADding deficient Xrn1 on NAD-capped RNA levels in cells and detected an elevation of total NAD-capped RNA in the $x r n 1 \Delta$ strain and even greater elevation in the $x r n 1-H 41 A$ knock-in strain (Fig. 4d). The latter is consistent with the H41A protein still maintaining its 5' monophosphate exonuclease activity and consequently leading to a higher relative level of NAD-capped RNA. Moreover, direct detection of the Cox 2 and $21 \mathrm{~S}$ rRNA 

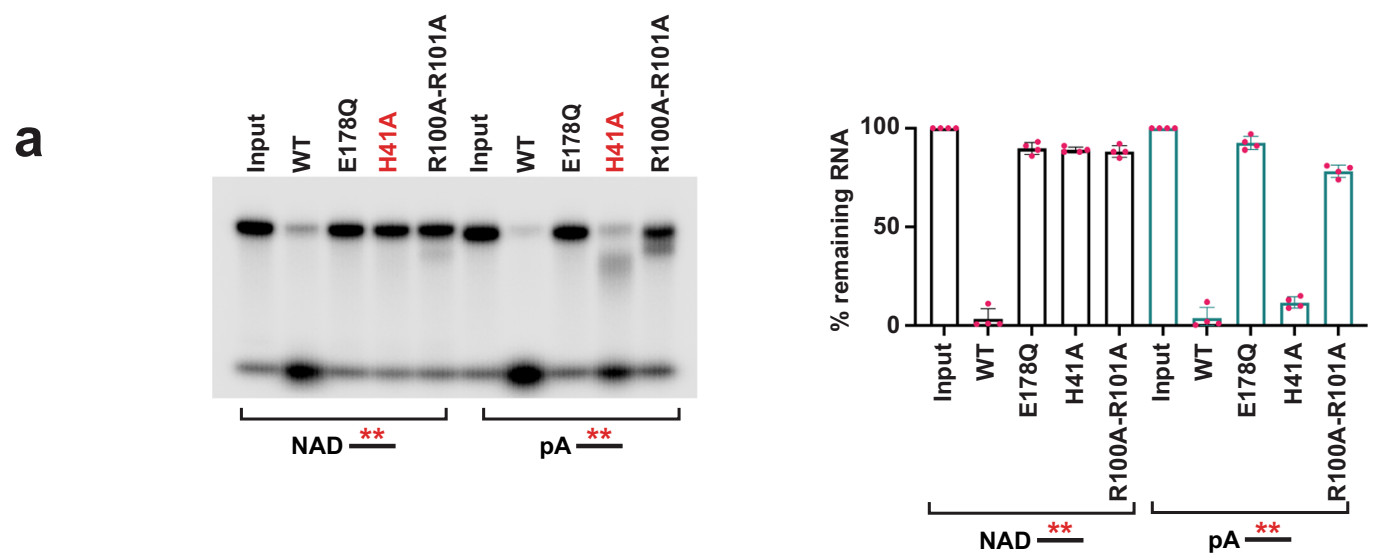

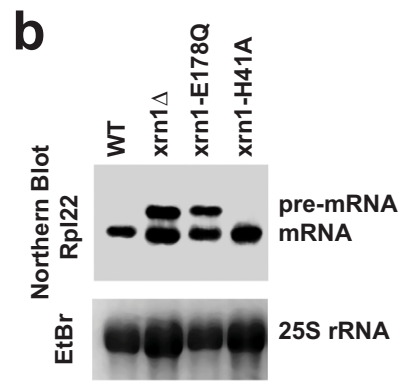

d

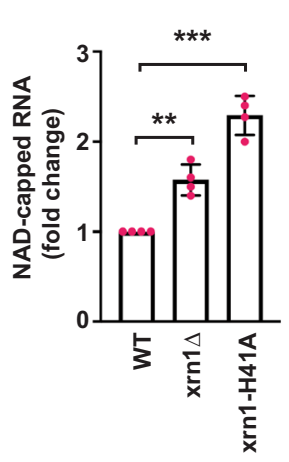

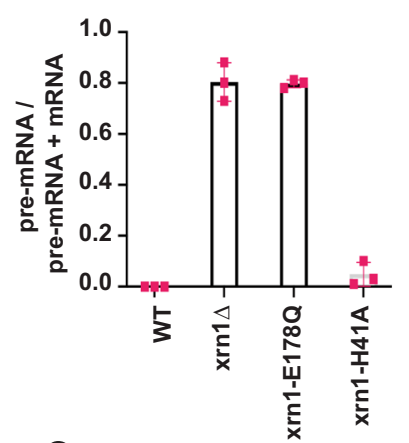

C

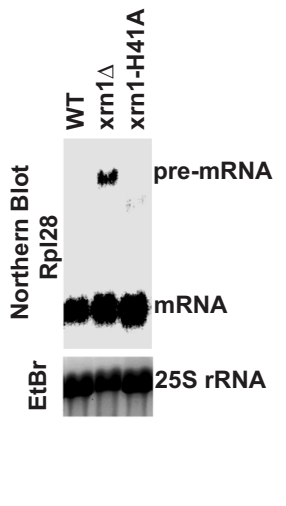

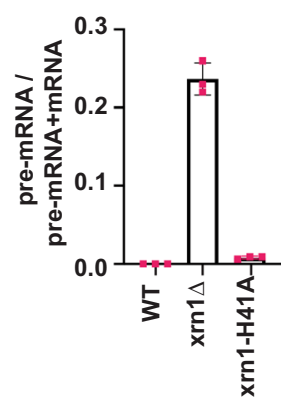

e
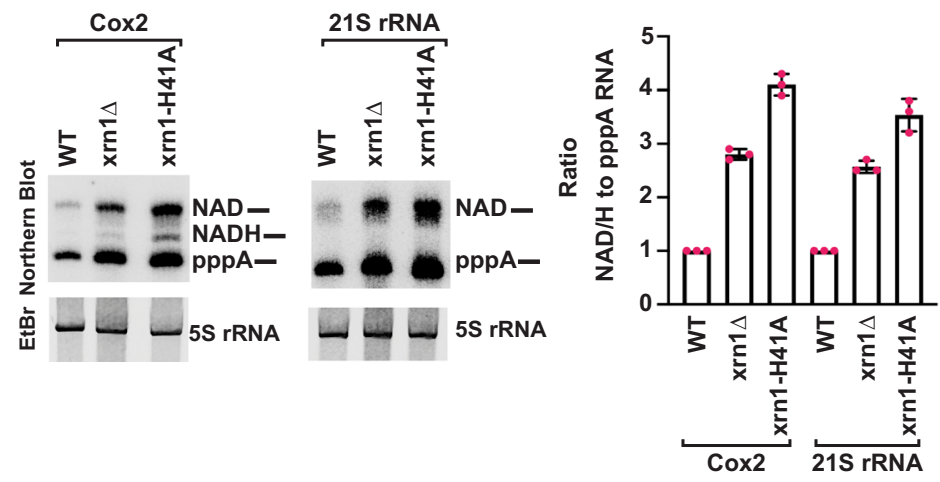

Fig. 4 A conserved histidine residue in the catalytic pocket of Xrn1 is indispensable for NAD-capped RNA hydrolysis. Xrn1 mutational screen revealed that H41 is indispensable for NAD-capped RNA hydrolysis. a $30 \mathrm{nM}$ recombinant WT or mutated Xrn1 from K. lactis was incubated with uniformly 32P-labeled 5'-monophosphate or NAD-capped RNA. The products were resolved by 15\% $7 \mathrm{M}$ urea PAGE gel. Quantitation from four independent experiments are presented on the right with the percent of full length RNA remaining. Error bars represent \pm SD. b Northern Blot for Rpl22 mRNA in WT, $x r n 1 \Delta, x r n 1-E 178 Q$, and $x r n 1-H 41 A$ knock-in mutant is shown. Quantitation from three independent experiments are presented on the right with the mean ratio of Rpl22 pre-mRNA over total (pre-mRNA + mRNA). Error bars represent \pm SD. c Northern Blot for Rpl28 mRNA in WT, xrn14 and xrn1-H41A knock-in mutant is shown. Quantitation from three independent experiments are presented on the right with the mean ratio of RPL28 pre-mRNA over total (premRNA + mRNA) for the WT, xrn14 and xrn1-H41A. Error bars represent \pm SD. d Total RNAs from WT, xrn14, xrn1-H41A strains were subjected to the NADcapQ assay to detect total level of cellular NAD-capped RNAs. Average from $n=4$ independent experiments are shown with error bars denoting \pm SEM. Statistical significance level was calculated by one-way ANOVA $(F=18.30, \mathrm{df}=2.209, p<0.0001)$ with a Dunnett's multiple comparison post hoc test, ${ }^{\star \star} p=0.0036,{ }^{\star \star \star} p=0.00013$. e Northern Blot analysis of DNAzyme-generated 5'-end-containing subfragments of Cox2 and $21 \mathrm{~S}$ rRNA from WT, xrn14 and $x r n 1-H 41 A$ grown in YPD (fermentation) media. Quantitation from three independent experiments with error bars representing \pm SD are shown on the right. Source data are provided in Source Data File.

mitochondrial transcripts by DNAzyme analysis revealed a fourand three-fold elevation of NAD-capped RNA in the xrn1-H41A strain, respectively (Fig. 4e). We conclude that $\mathrm{H} 41$ is a critical residue for the Xrn1-directed deNADding activity in cells and provides an avenue to directly determine the functional significance of Xrn1 deNADding in cells.
Xrn1 maintains NAD-capped RNA in mitochondria. The $5^{\prime}-3^{\prime}$ exonuclease activity of Xrn1 is known to be necessary for growth on nonfermentable carbon sources in yeast resulting in a slowgrowth phenotype in its absence ${ }^{35}$. We next determined whether Xrn1 deNADding activity contributed to the inhibitory growth on non-fermenting sugar utilizing the deNADding-deficient $x r n 1$ - 
a
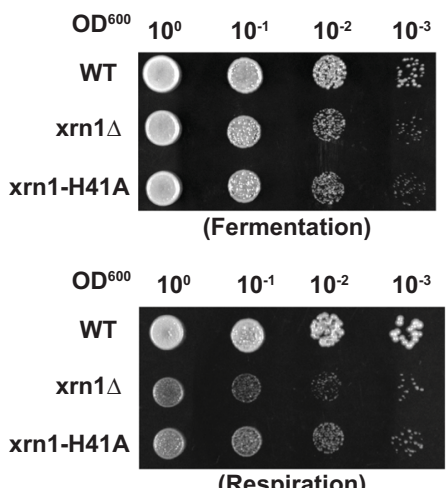

C

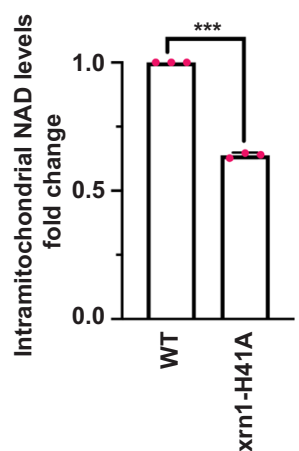

b
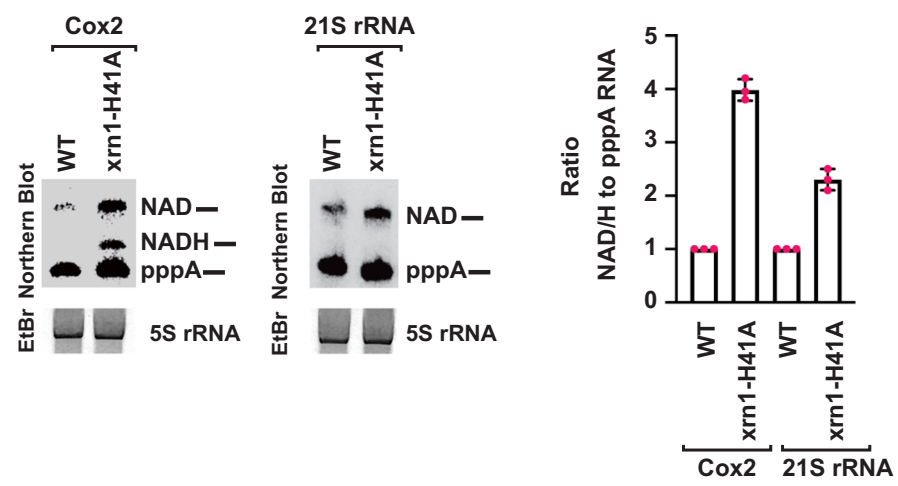

d

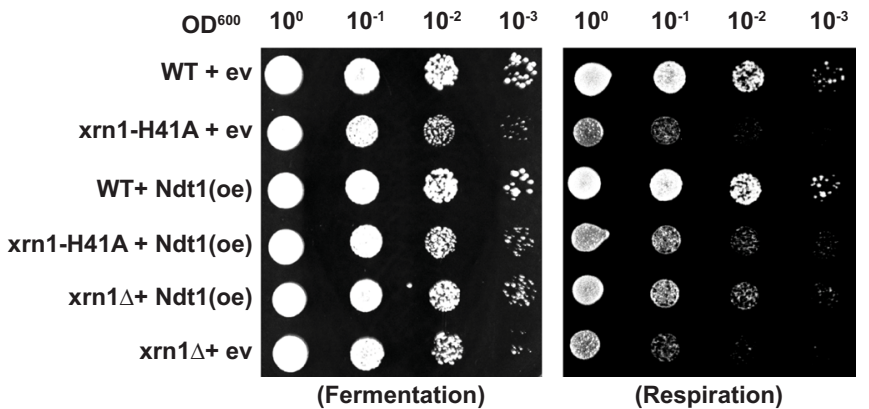

Fig. 5 Xrn1 deNADding activity is critical in maintaining intramitochondrial NAD steady state levels. a Tenfold serial dilution of WT, xrn14 and xrn1H41A were spotted onto solid YPD (Fermentation) and YPG (Respiration) plates and incubated at $30^{\circ} \mathrm{C}$. $\mathbf{b}$ Northern Blot analysis of DNAzyme-generated $5^{\prime}$-end-containing subfragments of Cox2 and 21S rRNA from WT, xrn1s and xrn1-H41A grown in YPG media with the quantitation on the right (Average of three independent experiments with error bars represent $\pm S D$ ). Source data are provided in Source Data File. c Intramitochondrial NAD/NADH levels in WT and xrn1-H41A cells grown on YPG. Data are presented relative to the WT cells set to 1 and derived from three biological replicates (Average of three independent experiments with error bars represent \pm SEM; two sided unpaired $t$ test; ${ }^{\star \star \star} p=0.000001$ ). Source data are provided in Source Data File. d Tenfold serial dilution of WT, xrn1 $1 \Delta$ and $x r n 1-\mathrm{H} 41 \mathrm{~A}$ harboring either an empty vector (ev) - without Ndt1 or a multicopy plasmid containing Ndt1 under a strong promoter-over expressed (oe) were spotted onto solid YPD and YPG plates and incubated at $30^{\circ} \mathrm{C}$.

H41A strain. As expected, all strains exhibited commensurate growth under fermentation growth parameters with glucose which would not require mitochondrial activity for growth (Fig. 5a). Interestingly, the deNADding compromised $x r n 1-H 41 \mathrm{~A}$ strain demonstrated a slow-growth phenotype comparable to the xrn1 deletion strain on glycerol as the non-fermenting carbon source (Fig. 5a) where mitochondrial activity is required for cellular energetics. Importantly, a corresponding increase in NAD-capped RNA was also evident in $x r n 1-H 41 \mathrm{~A}$ mutant mitochondrial RNA (Fig. 5b), indicating a correlation between NAD-capped RNA and cellular growth when mitochondrial function was essential.

To determine whether levels of NAD-capped RNA influenced overall mitochondrial NAD levels, NAD/H levels were determined from WT and $x r n 1-H 41 A$ mitochondria derived under respiring growth conditions. Our findings revealed a $\sim 35 \%$ reduction of intramitochondrial NAD levels in the $x r n 1-H 41 A$ mutant strain (Fig. 5c). With NAD-capped RNAs constituting a significant fraction of mitochondrial RNA in yeast ${ }^{22}$, these data imply NADcapped RNAs may function as a source of mitochondrial NAD. To further determine whether the observed slow growth phenotype of the $x r n 1-H 41 A$ strain was a consequence of reduced mitochondrial NAD levels, we overexpressed the main mitochondrial NAD transporter protein Ndt1, which leads to elevated intramitochondrial
$\mathrm{NAD}^{36}$. As shown in Fig. 5d, overexpression of Ndt1 reduced the slow growth phenotype observed in both the $x \mathrm{rn} 1 \mathrm{\Delta}$ and $\mathrm{xrn} 1$ $H 41 A$ strains demonstrating the lower levels of mitochondrial $\mathrm{NAD}$ are a contributing factor to the observed slow growth phenotype. We conclude Xrn1 can regulate mitochondrial NADcapped RNA through its deNADding activity and may link RNA metabolism to more general mitochondrial health and potential mitochondriopathies.

\section{Discussion}

Pyridine dinucleotides, particularly nicotinamide adenine dinucleotide (NAD) and its reduced form NADH are essential players in a variety of cellular processes, including energy metabolism, cellular signaling, and transcription ${ }^{1}$. Recent mass spectrometry $23,37,38$ and chemoenzymatic analysis ${ }^{23}$ of cellular transcripts in organisms representing all three kingdoms of life have revealed that these dinucleotides also serve as non-canonical $5^{\prime}$-end RNA caps ${ }^{12}$. Nevertheless, the precise role of these noncanonical caps remained unknown.

In the present study, we characterized cellular proteins from the yeast S.cerevisiae interacting with a $5^{\prime} \mathrm{NAD}$ cap using NAD cap RNA affinity purification (NcRAP) and mass spectrometry. Our data revealed that unlike the canonical $\mathrm{m}^{7} \mathrm{G}$ caps, the NAD cap do not interact with translational factors or proteins involved 
in cellular translation, suggesting that NAD-capped RNAs are unlikely to be translated in budding yeast, consistent with the lack of yeast extract supporting NAD-capped RNA translation in vitro ${ }^{39}$. Surprisingly, herein we revealed that highly conserved $5^{\prime}$-monophosphate (5'P)-specific $5^{\prime}-3^{\prime}$ exoribonucleases, Xrn1 and Rat1 along with its interacting partner Rail (yeast homolog of human DXO) can associate with and hydrolyze 5'NAD-RNA in vitro. Notably, similar to the DXO/Rail family of proteins, both Xrn1 and Rat1 release intact NAD from the NAD-capped RNA and have the capacity to regenerate NAD.

Another unexpected outcome of our study was the influence of Xrn1 on NAD-capped mitochondrial RNAs. Although Xrn1 has been reported to colocalize with P-body markers ${ }^{30}$, there were no previous indication of mitochondrial association. Our high resolution microscopy demonstrates in addition to the association with P-body markers, Xrn1 can also colocalized with a mitochondrial marker in yeast suggesting the modulation of mitochondrial NAD-capped RNA by Xrn1 is direct rather than indirect. Moreover, standard confocal imaging also revealed association of P-bodies with mitochondria, but interestingly, only if Xrn1 was also associated. Association of P-bodies on the surface of mitochondria has previously been reported ${ }^{29}$, whether such an interaction is directed through Xrn1 remains to be determined. Future high-resolution analysis of all three structures simultaneous will be necessary to more precisely determine their relative localization.

Although our initial objective was to identify NAD cap-binding proteins, the prominent proteins associated with the NAD cap were RNA nucleases and not bona fide NAD cap-binding proteins. This finding is consistent with our previous report that the NAD cap functions as a tag to promote rapid RNA decay ${ }^{3}$. It is possible that eukaryotic cells are devoid of NAD cap-binding proteins and NADcapped RNAs instead are recognized by RNA nucleases to rapidly clear the RNA. More refined attempts with extract derived from a stain lacking the three dominant NAD cap associated proteins, Xrn1, Rail and a conditional depletion of Rat1, may be required to detect additional bound proteins. In addition to Xrn1, we also demonstrated that Rat1 is capable of binding and hydrolyzing NAD-capped RNAs. Since Rat1 and Rail are primarily nuclear protein $s^{25}$ it is likely that their activity is predominantly on nuclear NAD-capped RNAs distinct from Xrn1. A more holistic and comparative analysis of the NAD-capped RNAs in the mutant strains of these three deNADding enzymes will aid in understanding their distinct or overlapping NAD-capped RNA substrates.

Mutational analysis of the catalytic center of Xrn1 led to the identification of a conserved histidine residue-His41, which is indispensable for deNADding, but does not significantly affect $5^{\prime}$ $\mathrm{P}$ hydrolysis. Consistent with the proposed contribution of $\mathrm{H} 41$ to enzyme processivity ${ }^{32}$, low levels of intermediates were detected with the H41A mutant protein. Nevertheless, the H41A protein was still capable of degrading RNA both in vitro ${ }^{32}$ (Fig. 4a) and in cells (Fig. 4b, c). Importantly, this residue allowed for the uncoupling of the deNADding activity of Xrn1 from the $5^{\prime}$ $\mathrm{P}$ exoribonuclease activity and enabled a delineation of the physiological role of NAD-capped RNA in yeast. Moreover, based on the observations of the xrn1-H41A knock-in mutant cells, we suggest that the previously characterized slow growth phenotype of $x r n 1 \Delta$ on non-fermenting sugar ${ }^{35}$ is likely due to the loss of deNADding activity and not its monophosphate directed RNA decay.

Identification of a mutation in $\mathrm{H} 41$ being able to support $5^{\prime} \mathrm{P}$ exoribonuclease activity was surprising, since two charged substitution within this residue were identified in a synthetic lethal screen with the $3^{\prime}$ exonuclease essential ski2 $\Delta$ mutant ${ }^{40}$ suggesting these substitutions disrupt Xrn1 exonuclease activity. However, analysis of recombinant Xrn1 harboring either the H41D or
H41R mutation reveals that only H41D disrupts $5^{\prime} \mathrm{P}$ exoribonuclease activity while H41R retains robust exonuclease activity (Supplementary Fig. 4b) suggesting a more complex contribution of H41 to Xrn1 function. Future structural analysis of the H41A apo protein and in complex with NAD cap will illuminate the mechanism by which it can support exonuclease activity but not deNADding.

The intracellular concentration of pyridine dinucleotides is tightly regulated in cells ${ }^{41}$. Interestingly, we observe $\sim 35 \%$ reduction in the intramitochondrial NAD levels in $x r n 1-H 41 A$ strains grown in YPG (non-fermenting sugar). Since mitochondria are indispensable for respiration, a decrease in NAD levels in mitochondria result in a significant slow growth phenotype upon growth on YPG media. It is important to note that mitochondria of budding yeast lack enzymes necessary for NAD synthesis and primarily rely on NAD imported from the cytoplasm ${ }^{42}$. In addition, the availability of free NAD dictates levels of mitochondrial NAD-capped RNA synthesis ${ }^{22}$. However, the full extent of Xrn1-H41A on mitochondrial NAD levels remains unclear since NAD-capped RNAs likely constitute $<1 \%$ of total mitochondrial NAD levels. Whether this indicates cytoplasmic H41A deNADding may also contribute to mitochondrial NAD levels or the pools of "free" NAD are a smaller fraction of the total NAD levels remains to be determined. Collectively, our data support a role of Xrn1 in the turnover of mitochondrial NAD-capped RNA that may contribute to mitochondrial NAD and cellular growth during respiration in budding yeast. A recent report in Arabidopsis thaliana reinforces the equilibrium between NAD caps and free NAD where stabilization of NAD caps leads to a decrease in free NAD and a compensatory increase in NAD production following stress ${ }^{13}$. Whether NAD molecules stored in the $5^{\prime}$ end of RNA are used in adverse scenarios like nutrient starvation or quiescence in mammalian cells and the contribution of Xrn1 in NAD levels will be an important area of future exploration.

\section{Methods}

Yeast growth and media. All Saccharomyces cerevisiae strains used in the present study were derived in the BY4741 strain background and their genotypes are listed in Supplementary Table 2. Yeast cells were grown at $30^{\circ} \mathrm{C}$ either in YPD (Dextrose) or YPG (Glycerol) (1\% w/v yeast extract, $2 \% \mathrm{w} / \mathrm{v}$ peptone, $2 \% \mathrm{w} / \mathrm{v}$ glucose/ glycerol). For tenfold serial dilution growth assays, yeast cells were grown overnight in YPD or YPG medium and diluted first to an OD600 of 1 and then serially 1 to 10. From each diluted cultures, $5 \mu \mathrm{L}$ was spotted onto a plate and incubated at $30^{\circ} \mathrm{C}$.

Plasmids construction and PCR mediated site-directed Mutagenesis. Polymerase chain reaction (PCR) amplification was conducted from the genomic DNA of $K$. lactis using XRN1 gene-specific primers listed in Table S2. The PCR product was gel purified and ligated into a pET-28 vector using In-Fusion ${ }^{\circledR}$ (Takara) cloning.

PCR mediated site-directed mutagenesis was used for introducing specific point mutations in the Xrn1 protein. PCR with Single-Primer Reactions IN Parallel (SPRINP) ${ }^{43}$ and high-fidelity-DNA polymerase was used. All the primers used for generating point mutations are listed in Supplementary Table 1 and all plasmids used are listed in Supplementary Table 2.

In vivo site-directed mutagenesis using Delitto Perfertto. Mutation substitution in the XRN1 gene was generated using Delitto Perfetto ${ }^{44}$. Briefly, a CORE (COunterselectable marker and Reporter gene)-URA3-kanMx was introduced into the Xrn1 locus proximal to His41 (for H41A) and Glu178 (for E178Q) using 40-nts flanking sequences for homologous recombination. In the second step, a PCR-amplified fragment containing the mutation of interest was transformed into the strain to enable integration and excise CORE cassette in the process. All point mutations were validated by DNA sequencing.

For the generation of Xrn1-GFP strain, CORE was introduced between residues 235 and 236 using 40-nts flanking sequences for homologous recombination, whereas for Edc3-mcherry the CORE was introduced adjacent to the stop codon. In the second step, a PCR-amplified fragment using pVT100U-mtGFP (Addgene) for Xrn1 and pFA6a-link-yomCherry-CaURA3 (Addgene) for Edc3-mcherry as a template containing the GFP and mCherry, respectively was transformed into the strain to 
enable integration and excise CORE cassette in the process. All knock-ins were validated by DNA sequencing.

Protein expression and purification. Recombinant proteins were expressed and purified using Nickel-NTA affinity purification. In brief, the ligated plasmid was transformed into chemical competent $E$. coli BL21 (DE3) cells by heat shock. $5 \mathrm{~mL}$ LB cultures containing $50 \mu \mathrm{g} / \mathrm{mL}$ kanamycin were inoculated with single colonies and grown overnight. These cultures were used to inoculate $1 \mathrm{~L}$ of the same medium and allowed to grow at $37^{\circ} \mathrm{C}$ until an OD600 of 0.5. Protein expression was induced with $0.25 \mathrm{mM}$ isopropyl D-thiogalactopyranoside (IPTG) and cells grown at $18^{\circ} \mathrm{C}$ on a shaker for $\sim 18 \mathrm{~h}$. Cells were collected by centrifugation, $5000 \mathrm{~g}$ for $15 \mathrm{~min}$.

For protein purification, cell pellets were thawed and resuspended in $\sim 60 \mathrm{~mL}$ of

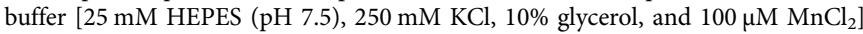
containing $0.4 \mathrm{mg} / \mathrm{mL}$ protease inhibitor phenylmethanesulfonylfluoride fluoride (PMSF). Cells were lysed by sonication, and the insoluble cell debris was separated by centrifugation. The Nickel-NTA affinity purification was performed as described previously ${ }^{45}$

In vitro transcription of NAD-capped RNAs. RNAs containing NAD and $\mathrm{m}^{7} \mathrm{G}$ cap structures were synthesized by in vitro transcription from a synthetic double stranded DNA template $\phi 2.5-\mathrm{NAD}-40$ containing the T7 $\phi 2.5$ promoter and a single adenosine within the transcript contained at the transcription start site (Supplementary Table 1$)^{10}$. For $\mathrm{m}^{7} \mathrm{G}$-capped RNA, $\mathrm{m}^{7} \mathrm{GpppA}$ RNA Cap Structure Analog (New England Biolabs) was included in the transcription reaction. In vitro transcription was carried out at $37^{\circ} \mathrm{C}$ overnight, using HiScribe ${ }^{\mathrm{TM}} \mathrm{T} 7 \mathrm{High}$ yield RNA Synthesis kit (New England Biolabs).

To generate ${ }^{32} \mathrm{P}$-labeled NAD-capped RNA, transcription was carried out in the presence of ${ }^{32} \mathrm{P}-\mathrm{NAD}$ (PerkinElmer) instead of ATP using \$2.5-AG-30 (Supplementary Table 1$)^{10}$. To generate ${ }^{32} \mathrm{P}$ uniformly labeled RNA, the transcription reactions were performed in the presence of $\left[\alpha^{32} \mathrm{P}\right]$ GTP.

NAD cap RNA affinity purification (NcRAP). 400 pmol of $\mathrm{NAD}$ and $\mathrm{m}^{7} \mathrm{G}$ capped RNAs were immobilized onto Dynabeads ${ }^{\mathrm{TM}}$ MyOne $^{\mathrm{Tm}}$ Streptavidin T1 (Invitrogen ${ }^{\mathrm{TM}}$ ) following manufacturer's instructions. For NcRAP, yeast cells were grown in YPD at $30^{\circ} \mathrm{C}$. $2 \mathrm{~L}$ of exponentially grown yeast cultures were harvested and lysed using mortar and pestle in liquid nitrogen. The cell powder obtained after grinding was resuspended in lysis buffer ( $25 \mathrm{mM}$ Tris- $\mathrm{HCl} \mathrm{pH} \mathrm{7.5,} 150 \mathrm{mM} \mathrm{CH}_{3} \mathrm{CO}_{2} \mathrm{~K}, 2.5 \mathrm{mM} \mathrm{Mg}$ $\left(\mathrm{C}_{2} \mathrm{H}_{3} \mathrm{O}_{2}\right)_{2}, 50 \mu \mathrm{M}$ EDTA, $50 \mu \mathrm{M}$ EGTA, $2.5 \%$ glycerol and $0.25 \%$ IPEGAL) along with complete EDTA-free Protease Inhibitor Cocktail (Roche) and incubated at $4{ }^{\circ} \mathrm{C}$ for $30 \mathrm{~min}$. Samples were subsequently centrifuged for $10 \mathrm{~min}$ at $5000 \mathrm{~g}$ to remove the cell debris. The clarified protein lysate was then transferred to a fresh $15 \mathrm{~mL}$ Falcon tube and the protein concertation was determined using a Bradford assay. $5 \mathrm{mg}$ of protein lysate was added to the pre-equilibrated (in $1 \mathrm{X}$ lysis buffer) NAD- or $\mathrm{m}^{7} \mathrm{G}$-capped RNA coupled Dynabeads in $2 \mathrm{~mL}$ microcentrifuge tubes. These tubes were next incubated at $4{ }^{\circ} \mathrm{C}$ on an end to end rocker for $90 \mathrm{~min}$. The beads were washed for at least 5 times with $1 \mathrm{X}$ lysis buffer, and the bound proteins were eluted with $2 \mathrm{X}$ Laemmli buffer (Bio-Rad Laboratories). The samples were incubated at $85^{\circ} \mathrm{C}$ for $5 \mathrm{~min}$ and were next run on Novex $^{\mathrm{mm}}$ WedgeWell ${ }^{\mathrm{TS}} 4-20 \%$, Tris-Glycine, Protein Gel (Thermo Fisher Scientific). The protein gel was stained with SYPRO Ruby (BioRad Laboratories) as per manufacturer's instructions and specific bands were sliced and sent for mass spectrometry based identification. In parallel we also analyzed the entire eluate using mass spectrometry. A complete list of identified proteins are provided in Supplementary Data 1.

\section{Liquid chromatography-tandem mass spectrometry (LC-MS/MS) for protein} identification. Mass spectrometry was carried out at Biological Mass Spectrometry Facility of Robert Wood Johnson Medical School and Rutgers, The State University of New Jersey. Each gel band was subjected to reduction with $10 \mathrm{mM}$ DTT for $30 \mathrm{~min}$ at $60 \mathrm{C}$, alkylation with $20 \mathrm{mM}$ iodoacetamide for $45 \mathrm{~min}$ at room temperature in the dark and digestion with $0.2 \mu \mathrm{g}$ trypsin (sequencing grade, Thermo Scientific Cat\#90058), and incubated overnight at $37^{\circ} \mathrm{C}$. Peptides were extracted twice with $5 \%$ formic acid, $60 \%$ acetonitrile and dried under vacuum.

Samples were analyzed by in-gel digestion and by LC-MS using Nano LC-MS/ MS (Dionex Ultimate 3000 RLSCnano System, Thermo Fisher) interfaced with Eclipse (Thermo Fisher) and loaded onto a fused silica trap column (Acclaim PepMap 100, $75 \mu \mathrm{m} \times 2 \mathrm{~cm}$, Thermo Fisher). After washing for $5 \mathrm{~min}$ at $5 \mu \mathrm{l} / \mathrm{min}$ with $0.1 \%$ TFA, the trap column was brought in-line with an analytical column (Nanoease MZ peptide BEH C18, 130A, $1.7 \mu \mathrm{m}, 75 \mu \mathrm{m} \times 250 \mathrm{~mm}$, Waters) for LC-MS/MS. Peptides were fractionated at $300 \mathrm{~nL} / \mathrm{min}$ using a segmented linear gradient $4-15 \%$ B in 30 min (where A: $0.2 \%$ formic acid, and B: $0.16 \%$ formic acid, $80 \%$ acetonitrile), $15-25 \% \mathrm{~B}$ in $40 \mathrm{~min}, 25-50 \% \mathrm{~B}$ in $44 \mathrm{~min}$, and $50-90 \% \mathrm{~B}$ in $11 \mathrm{~min}$. The next run starts following a return of Solution B to $4 \%$ for $5 \mathrm{~min}$. Mass spectrometry data were acquired using a data-dependent acquisition procedure with a cyclic series of a full scan with a resolution of 120,000 followed by MS/MS (HCD, relative collision energy 27\%) of the 20 most intense ions and a dynamic exclusion duration of $20 \mathrm{~s}$

The peak list of the LC-MSMS was generated by Thermo Proteome Discoverer (v. 2.1) into MASCOT Generic Format (MGF) and searched against the uniprot human fasta database and a database composed of common lab contaminants (CRAP) using in house version of X!Tandem (GPM Fury ${ }^{46}$ ). Search parameters are as follows: fragment mass error, $20 \mathrm{ppm}$; parent mass error, $\pm 7 \mathrm{ppm}$; fixed modification, carbamidomethylation on cysteine; variable modifications: methionine monooxidation for the primary search, asparagine deamination, tryptophan oxidation and dioxidation, Methionine dioxidation, and glutamine to pyro-glutamine were considered at the refinement stage. Protease specificity: trypsin $\mathrm{C}$-terminal of $\mathrm{R} / \mathrm{K}$ unless followed by $\mathrm{P}$ with 1 missed cleavage during the preliminary search and 5 missed cleavages during refinement. Minimum acceptable peptide and protein expectation scores were set at $10^{-2}$ and $10^{-4}$, respectively. The overall peptide false-positive rate ${ }^{47}$ was $0.07 \%$. We applied 15 counts as a cutoff to distinguish nonspecific interactors and contaminants. These data are presented as a separate sheet (Cutoff-15) in Supplementary Data 1 along with the raw data.

RNA in vitro deNADding assay. The ${ }^{32} \mathrm{P}-\mathrm{NAD}$-cap labeled and $\left[\mathrm{a}^{32} \mathrm{P}\right] \mathrm{GTP}$ uniformly labeled NAD-capped RNAs were incubated with the indicated amounts of recombinant protein in NEB buffer $3(100 \mathrm{mM} \mathrm{NaCl}, 50 \mathrm{mM}$ Tris- $\mathrm{HCl}, 10 \mathrm{mM}$ $\mathrm{MgCl}_{2}, \mathrm{pH}$ 7.9). Reactions were stopped by heating at $65^{\circ} \mathrm{C}$ for $5 \mathrm{~min}$. Decapping products were resolved by polyethyleneimine (PEI)-cellulose thin-layer chromatography (TLC) (Sigma-Aldrich) and developed in $0.45 \mathrm{M}\left(\mathrm{NH}_{4}\right)_{2} \mathrm{SO}_{4}$.

For in vitro $5^{\prime}$-end RNA decay, cell extract corresponding to $2 \mu \mathrm{g}$ of cellular protein from WT or $x r n 1 \Delta$ strains were incubated with $\left[\alpha-{ }^{32} \mathrm{P}\right] \mathrm{GTP}$ uniformly labeled NAD and $\mathrm{m}^{7} \mathrm{G}$ capped RNAs immobilized onto Dynabeads ${ }^{\mathrm{TM}}$ MyOne $^{\mathrm{TN}}$ Streptavidin T1 (Invitrogen ${ }^{\text {TM) }}$ ) in NEB buffer $3(100 \mathrm{mM} \mathrm{NaCl}, 50 \mathrm{mM}$ Tris- $\mathrm{HCl}$, $10 \mathrm{mM} \mathrm{MgCl}_{2}$, pH 7.9).

NAD-cap detection and quantitation (NAD-capQ). Yeast strains were grown in YPD media at $30^{\circ} \mathrm{C}$ according to standard protocols. All strains were harvested for the experiments at exponential phase (OD600 1) and total RNA was isolated using the acidic hot phenol method ${ }^{48}$. To remove residual free NAD, purified RNAs were dissolved in $10 \mathrm{mM}$ Tris- $\mathrm{HCl}(\mathrm{pH} \mathrm{7.5)}$ containing $2 \mathrm{M}$ urea. Samples were incubated $2 \mathrm{~min}$ at $65^{\circ} \mathrm{C}$ and immediately precipitated with isopropanol in the presence of $2 \mathrm{M}$ ammonium acetate. NAD-capQ was carried out as previously described $^{21}$. Briefly, $50 \mu \mathrm{g}$ of total RNA was digested with $2 \mathrm{U}$ of Nuclease P1 (Sigma-Aldrich) in $20 \mu \mathrm{L}$ of $10 \mathrm{mM}$ Tris (pH 7.0), $20 \mu \mathrm{M} \mathrm{ZnCl}_{2}$ at $37^{\circ} \mathrm{C}$ for $1 \mathrm{~h}$ to release $5^{\prime}$-end NAD. The control samples lacking Nuclease P1 were prepared by incubating $50 \mu \mathrm{g}$ of RNA treated with the same reaction condition. The NADH standard curve was generated for each experiment in the same buffer condition as above for assays containing nuclease P1. Following digestion with nuclease P1, $30 \mu \mathrm{L}$ of NAD/NADH Extraction Buffer (NAD/NADH Quantitation Kit, SigmaAldrich) was added to each sample. In the second step, $50 \mu \mathrm{L}$ samples were used in a colorimetric assay according to the manufacturer's protocol (NAD/NADH Quantitation Kit, Sigma-Aldrich) as described ${ }^{21}$.

Isolation of NAD-capped RNAs by NAD capture and RNA quantitation. Total RNA from yeast strains grown in YPD media was isolated with the acidic hot phenol method $^{48}$ and treated with DNase (Promega) according to the manufacturers' protocols. NAD-capped RNAs were isolated using the NAD-RNA capture protocol ${ }^{23}$ with minor modifications. NAD-capture was carried out with $50 \mu \mathrm{g}$ total RNA treated with $10 \mu \mathrm{L}$ 4-pentyn-1-ol (Sigma-Aldrich) and $3 \mathrm{U}$ Adenosine diphosphateribosylcyclase (ADPRC) in $100 \mu \mathrm{L}$ reaction containing $50 \mathrm{mM} \mathrm{HEPES,} 5 \mathrm{mM} \mathrm{MgCl}$ $(\mathrm{pH} 7)$ and $40 \mathrm{U}$ RNasin Ribonuclease Inhibitor (Promega) at $37^{\circ} \mathrm{C} 60 \mathrm{~min}$. The reaction was stopped with phenol/chloroform extraction and RNAs were precipitated with ethanol in the presence of $2 \mathrm{M}$ ammonium acetate. RNAs with a $5^{\prime}$-end NAD were biotinylated by treatment with a copper-catalyzed azide-alkyne cycloaddition (CuAAC) reaction by incubating with $250 \mu \mathrm{M}$ biotin-PEG3-azide, freshly mixed $1 \mathrm{mM}$ CuSO4, $0.5 \mathrm{mM}$ THPTA, $2 \mathrm{mM}$ Sodium Ascorbate in $100 \mu \mathrm{L}$ reaction with $50 \mathrm{mM}$ HEPES, $5 \mathrm{mM} \mathrm{MgCl}_{2}(\mathrm{pH} 7)$ and $40 \mathrm{U}^{\mathrm{RN} a s i n}{ }^{\oplus}$ Ribonuclease Inhibitor (Promega) at $30{ }^{\circ} \mathrm{C}$ for $30 \mathrm{~min}$. RNA was precipitated with ethanol in the presence of $2 \mathrm{mM}$ EDTA and $2 \mathrm{M}$ ammonium acetate. Biotinylated NAD-capped RNAs were captured by binding to $20 \mu \mathrm{L}$ streptavidin magnet beads (Nvigen) at room temperature with gentle rocking for $1 \mathrm{~h}$ in $100 \mu \mathrm{L}$ binding buffer $(1 \mathrm{M} \mathrm{NaCl}, 10 \mathrm{mM}$ HEPES (pH 7.5) and $5 \mathrm{mM}$ EDTA). The beads were washed three times with buffer containing $8 \mathrm{mM}$ Urea, $50 \mathrm{mM}$ Tris- $\mathrm{HCl}$ (pH 7.4), 0.1\% IPEGAL). To elute biotinylated NAD-capped RNAs, beads were resuspended in $100 \mu \mathrm{L}$ of above buffer, heated to $95^{\circ} \mathrm{C}$ for $5 \mathrm{~min}$ and RNA precipitated with ethanol in the presence of glycogen and $2 \mathrm{M}$ ammonium acetate. Captured NAD-RNAs were dissolved in $20 \mu \mathrm{L}$ $\mathrm{H}_{2} \mathrm{O}$ and reverse transcribed with $\mathrm{M}-\mathrm{MLV}$ reverse transcriptase, random hexamers, and oligo (dT) (Promega) according to the manufacturer's instructions. qRT-PCR was performed with the primers listed in Supplementary Table 1. qRT-PCR was carried out on QuantStudio 3 Real-Time PCR System (Thermo Fisher Scientific) with iTaq SYBR Green Supermix (Bio-Rad Laboratories).

Boronate affinity electrophoresis and Northern Blotting analysis of in vivo NAD-capped transcripts after DNAzyme-mediated RNA cleavage. For analysis of NAD and $\mathrm{NADH}$-capping during fermentation, yeast strains were grown in YPD and for respiration in YPG media at $30^{\circ} \mathrm{C}$. RNA was isolated from cells at the exponential phase (OD600 1) with the acidic hot phenol method ${ }^{48}$ and treated with DNase (Promega). $50 \mu \mathrm{g}$ of total cellular RNA was incubated with $1 \mu \mathrm{M}$ of the 
corresponding DNAzyme ((Supplementary Table 1) in $50 \mu \mathrm{L}$ reaction containing $10 \mathrm{mM}$ Tris $\mathrm{pH}=8.0,50 \mathrm{mM} \mathrm{NaCl}, 2 \mathrm{mM}$ DTT and $10 \mathrm{mM} \mathrm{MgCl}_{2}$. Samples were heated at $85^{\circ} \mathrm{C}$ for $2 \mathrm{~min}$ and slow cooled to $37^{\circ} \mathrm{C} . \mathrm{MgCl}_{2}$ was added to a final concentration of $10 \mathrm{mM}$ and incubated for $60 \mathrm{~min}$ at $37^{\circ} \mathrm{C}$. Reactions were terminated with $100 \mu \mathrm{L}$ of stop solution $(50 \mathrm{mM}$ Tris $\mathrm{pH} 8.0,20 \mathrm{mM}$ EDTA, and $0.1 \mu \mathrm{g} / \mathrm{mL}$ glycogen) and RNA was precipitated with $500 \mu \mathrm{L}$ ethanol by incubating for $30 \mathrm{~min}$ at $-80^{\circ} \mathrm{C}$ followed by centrifugation for $30 \mathrm{~min}$ at $16,000 \mathrm{~g}$ at $4{ }^{\circ} \mathrm{C}$. The supernatant was removed, and the pellet resuspended in $\mathrm{H}_{2} \mathrm{O}$.

To analyze NAD-capping of DNAzyme-generated fragments of mitochondrial RNAs, $25 \mu \mathrm{g}$ of cleaved RNA was separated by electrophoresis on $8 \%$ urea polyacrylamide gels supplemented with $0.3 \% 3$-acrylamidophenylboronic acid (Boron Molecular). RNA was transferred to positively charged Nylon transfer membrane (GE Healthcare Life Sciences), immobilized by UV crosslinking, and incubated with a ${ }^{32} \mathrm{P}$-labeled oligodeoxyribonucleotide probe complementary to the $5^{\prime}$-end fragments of target RNAs (Supplementary Table 1). The probes were labeled using T4 polynucleotide kinase (New England BioLabs) and $\left[\gamma^{-32} \mathrm{P}\right]$ ATP (Perkin Elmer). Reaction products were visualized with Amersham Typhoon RGB Biomolecular Imager (GE Healthcare Life Sciences) and bands corresponding to uncapped and NAD- or NADH-capped DNAzymes-generated fragments were quantified with IQ TL image analysis software.

\section{Isolation of mitochondria and quantification of intramitochondrial NAD levels.} Mitochondria were isolated using density-gradient centrifugation as previously described $^{49}$. Seven grams of exponentially grown cells were used to retrieve pure mitochondria from both YPD (fermentation) and YPG (respiration) cultures. Cells were first treated with Zymolyase (Sunrise Science Products) to generate spheroplasts, which were next lysed using a homogenizer. The unbroken cells, nuclei, and cell debris were next pelleted by three consecutive centrifuges-first for $5 \mathrm{~min}$ at $1500 \mathrm{~g}$ at $4{ }^{\circ} \mathrm{C}$, second at $3000 \mathrm{~g}$ for $5 \mathrm{~min}$ and the third one at $12,000 \mathrm{~g}$ for $15 \mathrm{~min}$. The resulting supernatant was next layered onto a sucrose gradient (15-60\%) and purified mitochondria were isolated using density gradient centrifugation $(134,000 \mathrm{~g}$ for $1 \mathrm{~h}$ ). The intact mitochondria forms a brown band at the 60-32\% sucrose interface. Mitochondrial preparation purity was assessed by Western blot analysis Anti-Cox2 (Anti-MTCO2 antibody [4B12A5] (ab110271)), and anti-Pgk1 ((PA5-28612) Invitrogen) antibodies were used to detect the respective proteins. For assessing the mitochondrial association of Xrn1, Xrn1-Strep-tag II strain was used. The Xrn1Strep-tag II strain was generated using homologous recombination of a PCR product amplified from a plasmid pTF277 (Addgene) containing 40-nts flanking sequences for homologous recombination. Xrn1 was detected using Strep Tag Monoclonal Antibody (GT517) (Invitrogen). A dilution of 1:2000 of all primary antibodies in PBST were used for Western Blotting. Secondary antibodies were diluted at 1:10,000.

Mitochondrial NAD levels were quantified from three independent mitochondrial preparations from both WT and $x r n 1-H 41 A$ strains using NAD/ NADH Quantitation Kit (Sigma-Aldrich). Mitochondrial extract corresponding to $10 \mu \mathrm{g}$ of protein from both WT and $x r n 1-H 41 A$ were used to determine NAD levels as per instructions provided in the kit.

Confocal and STORM Imaging of yeast cells. Yeast cells were grown to the early exponential growth phase (OD600 $\mathrm{nm}=0.4-0.7$ ) in synthetic complete medium containing $2 \%$ glucose. Confocal microscopy was performed without fixing the cells. Mitotracker ${ }^{\circledast}$ Deep Red FM (Cell Signaling Technology) was used for labeling mitochondria. Prior to imaging, $200 \mathrm{nM}$ of Mitotracker Deep Red FM (Cell Signaling Technology) was added to the media and the cells were incubated for $30 \mathrm{~min}$, after which cells were washed twice to remove excess of the dye. For super resolution STORM microscopy, mito- $\mathrm{RFP}^{50}$ was used for labeling mitochondria. Here cells were fixed with $3.7 \%$ formaldehyde in the growth medium at room temperature (RT, $20 \mathrm{~min}$ ) and washed with $1 \mathrm{X}$ phosphate-buffered saline (PBS) with sorbitol (137 mM NaCl; 3 mM KCl; 8 mM Na2HPO4; $1.5 \mathrm{mM} \mathrm{KH2PO4;} \mathrm{10 \%}$ (w/v) sorbitol; $\mathrm{pH} 7)$. Cell walls were partially removed by zymolase treatment $\left(15 \mathrm{~min}, 30^{\circ} \mathrm{C}\right)$. Cover glass (\#1.5 thickness) (Electron Microscopy Sciences) was treated with $1 \mathrm{M} \mathrm{HCl}$ extensively rinsed with distilled water and air dried. Cover glass was then treated with $100 \mu \mathrm{g} / \mathrm{ml}$ of poly-D-lysine for $2 \mathrm{~h}$ at RT, washed with $1 \mathrm{X}$ PBS and dried overnight. Cells were allowed to attach onto the treated cover glass before incubating with blocking solution (1X PBS/sorbitol, 5\% bovine serum albumin (BSA) and $0.1 \%$ Triton X-100) for $1 \mathrm{~h}$ at RT. Rabbit anti-RFP (Rockland) and a mixture of mouse anti-GFP 8H11, 12E6 and G1 (Developmental Studies Hybridoma Bank) were incubated with the samples overnight at $4{ }^{\circ} \mathrm{C}$. After removing the primary antibody solution, samples were washed with $1 \mathrm{X} \mathrm{PBS} /$ sorbitol, $1 \%$ BSA, $0.05 \%$ Triton X-100. Secondary antibodies containing goat antimouse $\mathrm{F}(\mathrm{ab})_{2}$ Atto 488 and goat anti-rabbit Alexa Fluor 647 were incubated in blocking solution for $1 \mathrm{~h}$ at RT. Secondary antibody solution was removed and samples were washed with $1 \mathrm{X}$ PBS/sorbitol, 1\% BSA, 0.05\% Triton X-100. Samples were mounted on imaging buffer ${ }^{51}$ containing: $50 \mathrm{mM}$ Tris.base, $\mathrm{pH} 8.0,10 \mathrm{mM}$ $\mathrm{NaCl}, 10 \%$ (wt/vol) glucose, $100 \mathrm{mM}$ monoethanolamide (MEA), $40 \mu \mathrm{g} / \mathrm{mL}$ catalase, and $0.5 \mathrm{mg} / \mathrm{mL}$ of glucose oxidase. MEA was used as a thiol compound to facilitate photo switching of dyes. Catalase and glucose oxidase used an oxygen scavenger system to reduce photo bleaching. Primary antibodies, Rabbit anti-RFP (Rockland), mouse anti-GFP 8H11, 12E6 and G1 (Developmental Studies Hybridoma Bank) were all diluted at 1:1000. Secondary antibodies were diluted at 1:5000.
STORM was set up on an Olympus IX73 with an excitation light source containing 405-nm, 470-nm, and 590-nm excitation wavelengths. An Olympus $60 \times 1.3$ N.A. UPlanSApo objective was used to acquire $512 \times 512$-pixel images using an Andor Zyla 4.2 sCMOS camera at 25 frames/s. A spinning disk was included in the emission light path to block out of focus light and retain fluorescence from a single optical plane. An IR focus lock system (zero drift correction) was used to ensure minimal drift in the $z$-axis. Software was used to correct for XY drift in the images by using the translational setting of the StackReg plugin from ImageJ. Fluorescent 10 -nm beads were used to determine the resolution of the system. As a measure of resolution, the full-width half mean of single beads were measured at $\sim 10 \mathrm{~nm}$.

Excitation light was adjusted to $0.2-1 \mathrm{~mW}$ at $470 \mathrm{~nm}$ and $0.2-1 \mathrm{~mW}$ at $590 \mathrm{~nm}$ to acquire a sparse subset of fluorophores. Intensities of excitation light were measured at the back of the objective. Streaming acquisition of images was sequentially acquired with $10-15 \mathrm{~ms}$ exposure time. On average, 10,000-50,000 images were acquired for each field of view. Images from a single focal plane were acquired. Blinking events were identified by the change in fluorescence at individual pixel regions between frames. Images reconstruction, chromatic aberration correction and drift correction were done using ThunderSTORM ${ }^{52}$.

Statistics and reproducibility. All statistical analysis and software used have been mentioned in the Figure Legends and Materials \& Methods. GraphPad Prism version 8.2.0 was used for all statistical analysis. The SyproRuby stained gels for NcRAP experiments shown in Fig. 1b and Supplementary Fig. 1b are representative figures that were carried out from three independent affinity purification experiments. The panels shown for in vitro RNA decay experiments in Fig. 2b, c, and in Supplementary Figs., $2 \mathrm{a}-\mathrm{c}$, f, and $4 \mathrm{~b}$ are representative of three independent experiments. TLC experiments in Fig. 2e and Supplementary Fig, 2e are representative of three independent experiments.

Reporting summary. Further information on research design is available in the Nature Research Reporting Summary linked to this article.

\section{Data availability}

The data supporting the findings of this study are available from the corresponding authors upon reasonable request. Mass Spectrometry is deposited at MassIVE under Accession code MSV000087605. Source data for the figures and supplementary figures are provided as a Source Data file. Source data are provided with this paper.

Received: 24 May 2021; Accepted: 18 January 2022; Published online: 16 February 2022

\section{References}

1. van der Knaap, J. A. \& Verrijzer, C. P. Undercover: gene control by metabolites and metabolic enzymes. Genes Dev. 30, 2345-2369 (2016)

2. Cahova, H., Winz, M. L., Hofer, K., Nubel, G. \& Jaschke, A. NAD captureSeq indicates NAD as a bacterial cap for a subset of regulatory RNAs. Nature 519, 374-377 (2015).

3. Jiao, X. et al. 5' end nicotinamide adenine dinucleotide cap in human cells promotes RNA decay through DXO-mediated deNADding. Cell 168, 1015-1027 e1010 (2017).

4. Walters, R. W. et al. Identification of NAD + capped mRNAs in Saccharomyces cerevisiae. Proc. Natl Acad. Sci. USA 114, 480-485 (2017).

5. Wang, Y. et al. NAD $(+)$-capped RNAs are widespread in the Arabidopsis transcriptome and can probably be translated. Proc. Natl Acad. Sci. USA 116, 12094-12102 (2019).

6. Bird, J. G. et al. The mechanism of RNA 5' capping with NAD+, NADH and desphospho-CoA. Nature 535, 444-447 (2016).

7. Hofer, K. et al. Structure and function of the bacterial decapping enzyme NudC. Nat. Chem. Biol. 12, 730-734 (2016).

8. Zhang, D. et al. Structural basis of prokaryotic NAD-RNA decapping by NudC. Cell Res. 26, 1062-1066 (2016).

9. Grudzien-Nogalska, E. et al. Structural and mechanistic basis of mammalian Nudt12 RNA deNADding. Nat. Chem. Biol. 15, 575-582 (2019).

10. Sharma, S. et al. Mammalian Nudix proteins cleave nucleotide metabolite caps on RNAs. Nucleic Acids Res. 48, 6788-6798 (2020).

11. Doamekpor, S. K., Gozdek, A., Kwasnik, A., Kufel, J. \& Tong, L. A novel 5'hydroxyl dinucleotide hydrolase activity for the DXO/Rail family of enzymes. Nucleic Acids Res. 48, 349-358 (2020).

12. Kiledjian, M. Eukaryotic RNA 5'-End $\mathrm{NAD}(+)$ capping and DeNADding. Trends Cell Biol. 28, 454-464 (2018).

13. Yu, X. et al. Messenger RNA 5' $\mathrm{NAD}(+)$ capping is a dynamic regulatory epitranscriptome mark that is required for proper response to abscisic acid in Arabidopsis. Dev. Cell 56, 125-140 e126 (2021). 
14. Topisirovic, I., Svitkin, Y. V., Sonenberg, N. \& Shatkin, A. J. Cap and capbinding proteins in the control of gene expression. Wiley Interdiscip. Rev. RNA 2, 277-298 (2011).

15. Stevens, A. Purification and characterization of a Saccharomyces cerevisiae exoribonuclease which yields 5'-mononucleotides by a 5' leads to 3' mode of hydrolysis. J. Biol. Chem. 255, 3080-3085 (1980).

16. Amberg, D. C., Goldstein, A. L. \& Cole, C. N. Isolation and characterization of RAT1: an essential gene of Saccharomyces cerevisiae required for the efficient nucleocytoplasmic trafficking of mRNA. Genes Dev. 6, 1173-1189 (1992)

17. Stevens, A. \& Poole, T. L. 5'-exonuclease-2 of Saccharomyces cerevisiae. Purification and features of ribonuclease activity with comparison to 5'exonuclease-1. J. Biol. Chem. 270, 16063-16069 (1995).

18. Xue, Y. et al. Saccharomyces cerevisiae RAI1 (YGL246c) is homologous to human DOM3Z and encodes a protein that binds the nuclear exoribonuclease Ratlp. Mol. Cell Biol. 20, 4006-4015 (2000).

19. Chang, J. H., Xiang, S., Xiang, K., Manley, J. L. \& Tong, L. Structural and biochemical studies of the 5'->3' exoribonuclease Xrn1. Nat. Struct. Mol. Biol. 18, 270-276 (2011).

20. Xiang, S. et al. Structure and function of the 5'->3' exoribonuclease Ratl and its activating partner Rail. Nature 458, 784-788 (2009).

21. Grudzien-Nogalska, E., Bird, J. G., Nickels, B. E. \& Kiledjian, M. "NAD-capQ" detection and quantitation of NAD caps. RNA 24, 1418-1425 (2018).

22. Bird, J. G. et al. Highly efficient 5' capping of mitochondrial RNA with $\mathrm{NAD}(+)$ and $\mathrm{NADH}$ by yeast and human mitochondrial RNA polymerase. Elife 7, https://doi.org/10.7554/eLife.42179 (2018).

23. Winz, M. L. et al. Capture and sequencing of NAD-capped RNA sequences with NAD captureSeq. Nat. Protoc. 12, 122-149 (2017).

24. Nubel, G., Sorgenfrei, F. A. \& Jaschke, A. Boronate affinity electrophoresis for the purification and analysis of cofactor-modified RNAs. Methods 117, 14-20 (2017).

25. Huh, W. K. et al. Global analysis of protein localization in budding yeast. Nature 425, 686-691 (2003).

26. Vaškovičová, K. et al. mRNA decay is regulated via sequestration of the conserved 5'-3' exoribonuclease Xrn1 at eisosome in yeast. Eur. J. Cell Biol. 96, 591-599 (2017).

27. Tesina, P. et al. Structure of the $80 \mathrm{~S}$ ribosome-Xrn1 nuclease complex. Nat Struct. Mol. Biol. 26, 275-280 (2019).

28. Decker, C. J. \& Parker, R. P-bodies and stress granules: possible roles in the control of translation and mRNA degradation. Cold Spring Harb. Perspect. Biol. 4, a012286 (2012).

29. Huang, L. et al. Mitochondria associate with P-bodies and modulate microRNAmediated RNA interference. J. Biol. Chem. 286, 24219-24230 (2011).

30. Sheth, U. \& Parker, R. Decapping and decay of messenger RNA occur in cytoplasmic processing bodies. Science 300, 805-808 (2003).

31. Endesfelder, U. \& Heilemann, M. Direct stochastic optical reconstruction microscopy (dSTORM). Methods Mol. Biol. 1251, 263-276 (2015).

32. Jinek, M., Coyle, S. M. \& Doudna, J. A. Coupled 5' nucleotide recognition and processivity in Xrn1-mediated mRNA decay. Mol. Cell 41, 600-608 (2011).

33. Celik, A., Baker, R., He, F. \& Jacobson, A. High-resolution profiling of NMD targets in yeast reveals translational fidelity as a basis for substrate selection. RNA 23, 735-748 (2017).

34. Dehecq, M. et al. Nonsense-mediated mRNA decay involves two distinct Upf1-bound complexes. EMBO J 37, https://doi.org/10.15252/embj.201899278 (2018).

35. Sinturel, F., Brechemier-Baey, D., Kiledjian, M., Condon, C. \& Benard, L. Activation of 5'-3' exoribonuclease Xrn1 by cofactor Dcs1 is essential for mitochondrial function in yeast. Proc. Natl Acad. Sci. USA 109, 8264-8269 (2012).

36. Agrimi, G. et al. Deletion or overexpression of mitochondrial NAD+ carriers in Saccharomyces cerevisiae alters cellular NAD and ATP contents and affects mitochondrial metabolism and the rate of glycolysis. Appl Environ. Microbiol. 77, 2239-2246 (2011).

37. Chen, Y. G., Kowtoniuk, W. E., Agarwal, I., Shen, Y. \& Liu, D. R. LC/MS analysis of cellular RNA reveals NAD-linked RNA. Nat. Chem. Biol. 5 , 879-881 (2009).

38. Wang, J. et al. Quantifying the RNA cap epitranscriptome reveals novel caps in cellular and viral RNA. Nucleic Acids Res. 47, e130 (2019)

39. Zhang, Y. et al. Extensive 5'-surveillance guards against non-canonical NADcaps of nuclear mRNAs in yeast. Nat. Commun. 11, 5508 (2020).

40. Page, A. M., Davis, K., Molineux, C., Kolodner, R. D. \& Johnson, A. W. Mutational analysis of exoribonuclease I from Saccharomyces cerevisiae. Nucleic Acids Res. 26, 3707-3716 (1998).

41. Canto, C., Menzies, K. J. \& Auwerx, J. NAD $(+)$ Metabolism and the control of energy homeostasis: a balancing act between mitochondria and the nucleus. Cell Metab. 22, 31-53 (2015)
42. Croft, T., Venkatakrishnan, P. \& Lin, S. J. NAD(+) Metabolism and regulation: lessons from yeast. Biomolecules 10, https://doi.org/10.3390/ biom10020330 (2020)

43. Edelheit, O., Hanukoglu, A. \& Hanukoglu, I. Simple and efficient site-directed mutagenesis using two single-primer reactions in parallel to generate mutants for protein structure-function studies. BMC Biotechnol. 9, 61 (2009).

44. Moqtaderi, Z. \& Geisberg, J. V. Construction of mutant alleles in Saccharomyces cerevisiae without cloning: overview and the delitto perfetto method. Curr. Protoc. Mol. Biol. 104, 13 10C 11-13 10C 17 (2013).

45. Song, M. G., Bail, S. \& Kiledjian, M. Multiple Nudix family proteins possess mRNA decapping activity. RNA 19, 390-399 (2013).

46. Craig, R. \& Beavis, R. C. TANDEM: matching proteins with tandem mass spectra. Bioinformatics 20, 1466-1467 (2004).

47. Gupta, N., Bandeira, N., Keich, U. \& Pevzner, P. A. Target-decoy approach and false discovery rate: when things may go wrong. J. Am. Soc. Mass Spectrom. 22, 1111-1120 (2011)

48. Kohrer, K. \& Domdey, H. Preparation of high molecular weight RNA. Methods Enzymol. 194, 398-405 (1991).

49. Gregg, C., Kyryakov, P. \& Titorenko, V. I. Purification of mitochondria from yeast cells. J. Vis. Exp. https://doi.org/10.3791/1417 (2009).

50. Westermann, B. \& Neupert, W. Mitochondria-targeted green fluorescent proteins: convenient tools for the study of organelle biogenesis in Saccharomyces cerevisiae. Yeast 16, 1421-1427 (2000).

51. Goossen-Schmidt, N. C., Schnieder, M., Huve, J. \& Klingauf, J. Switching behaviour of dSTORM dyes in glycerol-containing buffer. Sci. Rep. 10, 13746 (2020).

52. Ovesny, M., Krizek, P., Borkovec, J., Svindrych, Z. \& Hagen, G. M. ThunderSTORM: a comprehensive ImageJ plug-in for PALM and STORM data analysis and super-resolution imaging. Bioinformatics 30, 2389-2390 (2014).

\section{Acknowledgements}

The authors thank Liang Tong (Columbia Univ.) for helpful discussions and grateful to Kiledjian lab members for their input throughout the project and critical reading of the manuscript. The research was supported by NIH grant DC15000 to KYK and GM126488 to MK.

\section{Author contributions}

M.K., S.S. designed the experiments. S.S., J.Y., E.G.N., and K.Y.K. carried out the experiments. M.K. and S.S. wrote the manuscript with input from all coauthors.

\section{Competing interests}

The authors declare no competing interests.

\section{Additional information}

Supplementary information The online version contains supplementary material available at https://doi.org/10.1038/s41467-022-28555-7.

Correspondence and requests for materials should be addressed to Megerditch Kiledjian.

Peer review information Nature Communications thanks the anonymous reviewers for their contribution to the peer review of this work.

Reprints and permission information is available at http://www.nature.com/reprints

Publisher's note Springer Nature remains neutral with regard to jurisdictional claims in published maps and institutional affiliations.

Open Access This article is licensed under a Creative Common Attribution 4.0 International License, which permits use, sharing, adaptation, distribution and reproduction in any medium or format, as long as you give appropriate credit to the original author(s) and the source, provide a link to the Creative Commons license, and indicate if changes were made. The images or other third party material in this article are included in the article's Creative Commons license, unless indicated otherwise in a credit line to the material. If material is not included in the article's Creative Commons license and your intended use is not permitted by statutory regulation or exceeds the permitted use, you will need to obtain permission directly from the copyright holder. To view a copy of this license, visit http://creativecommons.org/ licenses/by/4.0/.

(C) The Author(s) 2022 